\title{
'Fado da Censura' de Fernando Pessoa: exemplo raro de poema de intervenção política destinado ao canto ${ }^{1}$
}

\author{
Armando Nascimento Rosa \\ Escola Superior de Teatro e Cinema \\ Instituto Politécnico de Lisboa, Portugal
}

DOI: https://doi.org/10.31492/2184-2043.RILP2020.37/pp.115-125

\begin{abstract}
Resumo
'Fado da Censura' é um poema não datado de Fernando Pessoa ortónimo que, pelo estilo e temática, pertence à derradeira fase da sua vida, num momento em que o poeta se vê em rota de colisão com a ideologia emergente do golpe militar de 1926, que implanta no país um regime ditatorial. O curioso deste texto pessoano, para além da temática de sátira política que o título denuncia, consiste em ser o único poema, que Pessoa nos legou, composto no formato de décimas, da tradição poética popular (as décimas integram uma quadra de mote, seguida de quarenta versos heptassilábicos, distribuídos por quatro estrofes de dez versos, cada uma delas terminando, em sequência, com um dos versos da quadra inicial) e que se assume, além do mais, como letra concebida para ser cantada em melodias do fado tradicional lisboeta. Importa analisar neste poema, tão deveras singular do corpus pessoano, o cruzamento entre a criação literária - inspirada nas formas da tradição popular de transmissão oral - e a expressão musical do canto como intervenção política, que faz parte do historial do fado, em especial desde o final de oitocentos às primeiras duas décadas do século XX.
\end{abstract}

Palavras-chaves: Fernando Pessoa; poesia; canto; fado; censura; sátira política.

\section{Abstract}

'Fado da Censura' is an undated poem by Fernando Pessoa (signed as orthonym) that, by style and theme, belongs to the last phase of his life, at a time when the poet finds himself on a collision course with the ideology emerging from the 1926 military coup, one which implements a dictatorial regime in the country. The curious thing about this text by Pessoa, besides the theme of political satire that the title denounces, is that it is the only poem, which Pessoa bequeathed to us, composed in the format of stanza called "décimas", from the popular poetic tradition ("décimas" is composed of a quatrain as motto, followed by forty heptasyllabic verses, spread over four stanzas of ten verses, each ending, in sequence, with one of the verses of the initial quatrain) and which is assumed, moreover, as a lyric designed to be sung in melodies of traditional Lisbon fado. It is important to analyze in this poem, really so unique among Pessoa's work, the intersection between literary creation - inspired by the forms of popular tradition based on oral transmission - and the musical expression of singing as a political intervention, which is part of the History of fado, especially since the end of the XIXth century til the first two decades of the twentieth century.

Keywords: Fernando Pessoa; poetry; song; fado (music genre); censorship; political satire.

1. Uma versão inicial deste artigo foi originalmente apresentada em Paris a 7 de Junho de 2017, em língua francesa, com o título: «'Fado de la Censure': un exemple rare de la poésie d'intervention politique destinée à être chantée dans l'œuvre de Fernando Pessoa»; comunicação apresentada, com tradução de Clara Ploux, na sala Fustel de Coulanges da École Normale Supérieure, na sessão de abertura do Colóquio Internacional 'Censure et Style', (7-9/6/2017), a convite de Cristina Marinho e Jean-Baptiste Amadieu, numa co-organização entre o Centro de Estudos Teatrais da Universidade do Porto, o Collège de France, a École Normale Supérieure e a Sorbonne. 


\section{(...) a canção é uma poesia ajudada (...)}

- Fernando Pessoa

\section{Introdução}

'Fado da Censura' é um poema verdadeiramente único na infinitude da obra de Fernando Pessoa. A sua singularidade provém em primeiro lugar da forma literária em que Pessoa o escreve. Uma forma que caracteriza a chamada poesia popular, que era normalmente praticada por autores analfabetos ou com uma baixa literacia. Designa-se por décimas, esta forma poética fortemente ligada a um contexto de transmissão oral, em que a rima é a garantia da memorização. As décimas são constituídas, como o próprio nome indica, por estrofes de dez versos. Na totalidade, são poemas de 44 versos, existindo uma quadra inicial que é o chamado mote, seguida de quatro estrofes com dez versos, e cada uma delas encerrando com um dos versos da quadra que deu o mote, até perfazer os quatro versos que a integravam. Não há notícia de que Pessoa haja escrito outros poemas no formato de décimas. Autor de centenas de quadras, como ele lhe chamou, ao gosto popular, o certo é que só por uma vez ele fez o exercício de colocar no seu rosto a máscara dos poetas populares, que recitavam as suas rimas e as difundiam em folhetos de cordel e, como acontece neste caso em especial, se destinavam a ser cantadas em música de fado. De facto, a forma poética das décimas surge associada ao género do fado; não sendo porém a sua forma lírica mais arcaica, ela torna-se muito comum nas letras cantadas em fado, sobretudo no último quartel do séc. XIX até aos inícios do séc. XX, e vai sendo a partir de então cada vez mais rara nas letras desta forma de canto. Parece haver duas razões fundamentais que levam ao progressivo abandono das décimas como letras de fado, na primeira década de novecentos. Por um lado, o advento das gravações de estúdio para a difusão do fado, nos discos de 78 rotações, não se mostra compatível com o formato das décimas que, pelo número de versos exigido, fazia com que o tema fosse sempre uma cantiga de longa duração. A difusão comercial do disco e, mais tarde, radiofónica, estimula o quase desaparecimento destas líricas, anteriormente tão populares, por permitirem ao fadista entregar-se a uma narrativa cantada plena de detalhes pitorescos, justamente dada a sua generosa extensão. A outra das razões deste abandono deve-se à emergência da profissionalização de músicos e cantores de fado, realizada em torno da criação das chamadas casas de fado. De canção urbana com origens marginais, que acompanham a vida boémia, interpretada por vozes de vocação espontânea em tabernas e prostíbulos dos bairros mais antigos de Lisboa (a primeira figura mítica no historial do fado é Maria Severa Onofriana, 
uma mulher pobre que ganhava a vida como prostituta, nascida em Lisboa em 1820, e falecida com 26 anos de idade, a 30 de Novembro de 1846, curiosamente o mesmo dia em que Pessoa viria a morrer no século seguinte), o fado, em face da sua imensa popularidade, que é transversal às proveniências sociais e culturais de ouvintes e cantadores, passa a institucionalizar-se enquanto actividade profissional lucrativa nos primórdios do século passado. Ora reside aqui a outra das duas razões mencionadas: a longa extensão dos temas de fado com letras em décimas pode tornar menos cativante a recepção do espectador/consumidor das novas casas de fado; lugares que tornam o fado na poderosa atracção turística que ele é hoje, mais do que nunca, um século depois - após a sua classificação como património cultural imaterial da humanidade, pela UNESCO, em 2011. Este menor apelo do fado em décimas resulta enfim da entrada do fado nos mecanismos do consumo do espectáculo ao vivo, por via também de alguma eventual monotonia melódica, que irá ser contrariada, por seu turno, pelo aumento de importância do fado com refrão - e refrão é coisa que não é possível forjar numa letra em décimas. Recordo-me de ouvir em entrevistas Alfredo Marceneiro - paradigmático intérprete, letrista e compositor de fado, que protagoniza uma transição de épocas nesta arte poético-musical - lamentar bastante o facto do público das casas de fado manifestar cada vez menor disponibilidade para ouvir e fruir fados com letras extensas. Alfredo Marceneiro (1891-1982), criador de um repertório onde existem e persistem fados com líricas de décimas em pleno século XX, salienta (no documentário televisivo Alfredo Marceneiro, realizado por Luís Gaspar para a RTP em 1979) que existe um prazer próprio do autêntico apreciador de fado, e que consiste em este ser capaz de saborear a demora de uma letra cantada, com todo o seu aparato narrativo e de evocação imagética.

É esse espaço expressivo que Pessoa deseja acentuar ao escolher as décimas para este seu fado de explícita intervenção política, denunciando a implantação da censura no Portugal em regime de ditadura que passaria, em 1933, a ser explicitamente liderada por Salazar.

Divulgado e publicado já no século XXI (no terceiro volume da poesia ortónima, em 2006, por Manuela Parreira da Silva, Madalena Dines e Ana Maria Freitas), alinhado entre a poesia não datada, o texto de 'Fado da Censura' apresenta-se no espólio do poeta, depositado na Biblioteca Nacional em Lisboa, numa folha única dactilografada, sem menção da data em que foi escrito. Quando me confrontei com o poema editado em livro, supus que Pessoa o tivesse redigido num dos seus derradeiros anos de vida (1934 ou 1935), visto que é por estas datas que se concentra um grande número de poemas de crítica ou sátira cujo alvo é Salazar e a repressão política e mental do Estado Novo recém-implantado - já na 
sua edição, Manuela Parreira da Silva situa a escrita do poema no arco temporal que vai de 1927 a 1935 (in Pessoa, 2006, p. 586). Ao serem revelados estes poemas de protesto, nos quais a arma do humor virulento é uma constante, eles contribuíram decisivamente para desmantelar um preconceito erróneo que consistiria em caracterizar Pessoa, de forma grosseira e monolítica, como um simpatizante da ideologia fascista. Se há textos anteriores em que o elitismo nacionalista de Pessoa o leva ao elogio do autoritarismo, ou ao seu fascínio pueril pela figura providencial sebastianista - refiro-me ao poema que ele dedicara em 1920 ao presidente assassinado Sidónio Pais -, a sua experiência de convívio com um status quo de censura à livre e plural expressão do pensamento irá conduzi-lo à síntese da sua nota auto-biográfica de 1935, em que se afirma como "cristão gnóstico, e portanto inteiramente oposto a todas as Igrejas organizadas", e onde identifica os três inimigos prioritários que é preciso combater: "a Ignorância, o Fanatismo, e a Tirania" (Pessoa, 1986, p. 252).

O investigador José Barreto, no prefácio a uma extensa e recente antologia onde reúne prosa e poesia que Fernando Pessoa produziu acerca de temáticas de intervenção política, escreve: “O fascismo é rotulado [por Pessoa] em vários textos aqui reunidos como uma tirania." (in Pessoa, 2015, p. 20). Ou ainda, mais adiante: «refira-se, enfim, uma curiosa ideia de Pessoa, exposta numa carta a Gaspar Simões de 1931, segundo a qual tanto o fascismo como o comunismo eram 'seitas religiosas' de 'misticismo político' (in Pessoa, 2015, p. 47). Essa ideia faria mais tarde escola e recolhe hoje o favor de historiadores dos regimes totalitários que adoptam o conceito de 'religiões políticas'» (in Pessoa, 2015, p. 22). Nesta antologia de textos de Pessoa, intitulada Sobre o Fascismo, a Ditadura Militar e Salazar (2015), José Barreto destaca o seguinte excerto revelador de um artigo de Pessoa. «Em fins de 1932, quando o fascismo italiano contava dez anos e o comunismo soviético quinze, Pessoa escreveu o trecho seguinte: “Quem hoje prega a sindicação, o estado corporativo, a tirania social, seja fascismo ou comunismo, está dissolvendo a civilização europeia; quem defende a democracia e o liberalismo, está defendendo-a"» (in Pessoa, 2015, p. 25).

"De todas as formas de reduzir à sua absurda proporção os tiranos, o riso é a arma mais devastadora." (Correia, 2015, p. 681) Assim o escreveu Natália Correia, em comentário escrito acerca da sua peça $O$ Homúnculo - tragédia jocosa (1965), em que o ditador é alvo de dramatúrgica sátira. Tal como o será nesta peça corajosa de Natália, também o humor dos poemas políticos de Pessoa contra Salazar, muitos deles escritos no último ano de vida do escritor, é uma catarse liberadora do poeta inconformado. Humor também de melancólica e amarga ironia, como é o caso do poema, escrito a um mês da sua morte física, e que 
considero um testamento de poeta entristecido com o estado de coisas desse seu país, asfixiado pelo fascismo clericalista de Salazar - para fazer uso da expressão que a oposição clandestina utiliza no final dos anos 20. Trata-se do poema em quadras 'Meu pobre Portugal'; publicado em 1995 por Teresa Rita Lopes (que transformei em canção em 2012, com a colaboração de António Neves da Silva, em cuja parceria desenvolvo o projecto de criação musical sobre poesia pessoana: O Piano em Pessoa).

E já agora, num parêntesis justificado pelo lugar primeiro de apresentação do presente artigo (em Paris, sob a forma de conferência, na Sala Fustel de Coulanges, da École Normale Supérieure), importa referir que um dos mais belos poemas que Pessoa escreve em língua francesa data também deste período, mais precisamente, uma semana antes da sua morte. Embora os seus conhecimentos de língua francesa não se comparassem com o domínio excepcional que manifestava na língua inglesa (visto que toda a sua escolaridade foi feita em inglês, na África do Sul, na cidade de Durban, uma vez que o padrasto aí exerceu funções de cônsul na então colónia britânica de Natal), tal não impediu que Pessoa tivesse composto poesia directamente em francês - para além de reflexões e comentários em prosa nesta língua. É esse o caso de 'Ma Blonde'; um poema de amor a uma loura que nos é desconhecida - mas cuja musa é muito provavelmente a inglesa Madge Anderson, com quem Pessoa terá nutrido um envolvimento sentimental no final da sua vida (Barreto, 2017, p. 599). Revisitando o universo da chanson française - para o qual o poema de Pessoa nos encaminha -, 'Ma Blonde' é uma canção que compus há várias décadas, inicialmente incluída na banda sonora da primeira das minhas peças pessoanas (Audição - com Daisy ao vivo no Odre Marítimo, publicada em 2002 e estreada em Lisboa no ano seguinte, no Teatro Maria Matos, encenada por Élvio Camacho, com direcção musical de Filipe Raposo) e incluída em 2018 na edição fonográfica O Piano em Pessoa.

Voltando à datação do poema em foco neste artigo, a mera conjectura que me ocorrera quanto à data de escrita do 'Fado da Censura' não é porém sustentável à luz da argumentação de José Barreto na obra atrás citada. Barreto propõe a data de 1927 como a mais provável para a composição do poema (in Pessoa, 2015, p. 94). Em 1927, um ano depois do golpe militar que instaura a ditadura em 28 de Maio de 1926, ocorre uma tentativa frustrada para derrubar o poder, em que o centro das operações se situa no Hotel Bristol, em S. Pedro de Alcântara (Lisboa), a 7 de Fevereiro de 1927. Ora na identificação ao alto da página do dactiloscrito onde surge o poema, lê-se 'Cantiga de Bristol', numa clara remissão que Pessoa faz para esta tentativa malograda de revolta contra a ditadura militar que governa o país (in Pessoa, 2006, p. 586); e acerca da qual, aliás, Pessoa começou por 
redigir uma inflamada e muito ambígua defesa do regime (de tal forma que esta defesa não colheu as simpatias desse mesmo regime, tendo sido censurada a sua primeira versão de 1927), no texto O Interregno, escrito de que Pessoa viria a arrepender-se face ao rumo dos acontecimentos no país. 'Fado da Censura' parece ser por isso também a maneira poética e satírica que Pessoa encontra para corrigir essa mesma mão que assinara o texto prolixo e infeliz de justificação (mesmo se numa argumentação bem pouco ortodoxa) do estado ditatorial. E uma vez que é o regime da ditadura militar que institui a censura, afigura-se bem plausível a tese de datação de 1927, avançada por José Barreto (o investigador sublinha ainda que o dactiloscrito parece ser coevo do poema 'Ai, Margarida', do heterónimo Álvaro de Campos, datado de 1 de Outubro de 1927 - e que, curiosamente, Mário Laginha viria a musicar em 2013 para a voz do fadista Camané).

$\mathrm{Na}$ sua edição do poema pessoano, Manuela Parreira da Silva avança com uma outra e sugestiva possibilidade de compreender a expressão 'Canção de Bristol', pois esta pode ser "uma referência ao Bristol Club", no coração da vida nocturna da Lisboa dos anos 20, "lugar de encontro dos modernistas" (in Pessoa, 2006, p. 586), que a ditadura mandou encerrar portas no início de 1928 (Barreto, 2012, p. 1)

Esta designação de 'Cantiga de Bristol' reforça um aspecto muito relevante para uma aproximação precoce que tenho mantido longamente, enquanto autor e intérprete musical, para com alguma da poesia de Pessoa, em especial aquela que ele assinou com o seu nome próprio, ou seja, a poesia ortónima, portuguesa e inglesa. Refiro-me à ligação profunda de Pessoa com a criação musical e, em especial, com a poesia cantada, que está perfeitamente explícita em 'Fado da Censura'. Quase tudo o que diz respeito à recepção da obra de Pessoa foi tardio no tempo. E também assim sucedeu com a tomada de consciência de que o poeta escreve versos a pensar numa voz que os canta; isto é, Pessoa compõe frequentemente poemas como se estivesse de facto a escrever letras de canções. Mário Pacheco, guitarrista e compositor que assina várias composições notáveis com poemas de Pessoa para vozes do fado (desde 'Na ribeira deste rio', tema que se destinava ao derradeiro disco que Amália Rodrigues já não concretizou, e acabou sendo gravado por Paulo Bragança, em 1996), dizia-me isto precisamente, quando o indaguei em Alfama no, por ele fundado, Clube de Fado, sobre a experiência de compor a partir dos versos de Pessoa; “já está tudo lá”, afirmava-me Mário Pacheco, em 2017, querendo com isto dizer que o trabalho do compositor se encontra previamente facilitado, porque tais poemas pessoanos possuem à partida tudo para se tornarem em canções. Com efeito, existem inúmeros poemas de Pessoa que surgem pensados para o canto, na sua métrica, na sua organização frá- 
sica e semântica, bem como nos esquemas da rima. Em 'Fado da Censura', esta intenção é deliberada e Pessoa recupera inclusive uma tradição, presente desde o século XIX, de um fado com letra de protesto político. Existe com efeito uma tradição de fado operário, de temática anarquista ou anti-monárquica. Uma tradição em que o fado é uma canção de intervenção política e que, por isso, mesmo, será abafada e censurada pela ditadura de Salazar. Quer isto dizer que o simples facto de Pessoa escolher exprimir a sua sátira contra a censura sob a forma de um fado em décimas, estava ao mesmo tempo a cultivar uma tradição associada ao fado que o regime salazarista desejava eliminar. Veja-se o diagnóstico essencial que a este propósito é feito pelo musicólogo e historiador do fado Rui Vieira Nery.

\begin{abstract}
“O Estado Novo (...) proclamava como seus fundamentos espirituais a fidelidade ao Catolicismo como religião oficial do Estado e a defesa da família, da moral e dos bons costumes no seio da sociedade. $\mathrm{O}$ Fado, comprovadamente, nasceu num contexto social marginal, de tabernas e bordéis, e assumia até com orgulho como ícone fundador a figura de uma prostituta da Mouraria, Maria Severa Onofriana. A nova ordem política assentava na negação do conflito de classes no seio da sociedade, e na possibilidade de conciliação harmónica dos interesses de patrões e trabalhadores no quadro do sistema corporativo. O Fado tinha na sua memória décadas de associação ao movimento operário e às suas expressões políticas socialistas, anarquistas e comunistas, com letras militantes subversivas que apelavam frequentemente à supressão da propriedade privada e à posse colectiva dos meios de produção" (Nery, 2016, pp. III-IV).
\end{abstract}

Esta antiga vocação do fado como canção de protesto político é uma memória subversiva que o regime salazarista procura apagar a todo o custo, se bem que a arte de poetas, de músicos e de intérpretes, consiga, pontualmente, desafiar a censura, como disso é exemplo o fado 'Abandono', gravado por Amália Rodrigues em 1962, com letra de David Mourão Ferreira e música de Alain Oulman; um tema que poeticamente retrata alguém que é feito prisioneiro "por seu livre pensamento" numa prisão junto ao mar, facilmente identificável com o Forte de Peniche, utilizado como calabouço para prisioneiros políticos - e por isso a canção passou a ser conhecida como o 'Fado Peniche' (Santos, 2014, p. 653). É muito surpreendente o facto de Amália nunca ter cantado versos de Pessoa, não obstante ter trazido tantos grandes poetas para o fado (para além de si mesma como autora que foi); em especial pela mão do mais importante e revolucionário dos compositores de fado que para ela escreveram música: Alain Oulman (19281990), nascido em Portugal de pais franceses, e expulso do país como exilado político em 1966. Como o confessou em entrevista, Amália achava que a poesia de Pessoa era mais para ser lida e pensada do que para o canto (Santos, 2014, pp. 575-576), e este foi um encontro de titãs que não aconteceu - certamente que esta convicção amaliana terá tido um eco mútuo no próprio Alain Oulman, que, 
também ele, nunca musicaria versos de Pessoa. Seria uma outra voz a estrear em fado um poema de Pessoa: Maria da Fé, com o poema em quadras 'Sino da minha aldeia', na música tradicional do Fado das Horas, incluído em álbum seu de 1964. A cantar Pessoa em fado, Maria da Fé seria seguida, alguns anos depois por: Maria do Rosário Bettencourt que gravou, a partir de 1968, vários fados com poemas pessoanos, entre eles 'Vontade e pensamento' (sobre fado de Joaquim Campos); ainda em 1968, por Teresa Silva Carvalho, com ‘Sol nulo nos dias vãos', no Fado Menor do Porto (de José Joaquim Cavalheiro Júnior); e por Tereza Tarouca, em 1970, com 'Cai chuva do céu cinzento', de novo no Fado das Horas, na versão de Maria Teresa de Noronha (Rosa, 2018, pp. 10-11).

A relação de Fernando Pessoa com o fado merece um estudo ainda a realizar. Há vários poemas seus em quadras que se referem ao fado como música, e solicitam o canto; outros ainda utilizam a palavra, mas enquanto sinónimo de destino. E existe um texto de síntese reflexiva, para um inquérito de imprensa, "O Fado e a Alma Portuguesa", datado de 1929, onde Pessoa exercita a arte da máxima enigmática e do paradoxo desconcertante e insere essa espantosa formulação, que escolhi para epígrafe desta comunicação, de que "a canção é uma poesia ajudada":

\footnotetext{
"Toda a poesia - e a canção é uma poesia ajudada - reflecte o que a alma não tem. Por isso a canção dos povos tristes é alegre e a canção dos povos alegres é triste.

O fado, porém, não é alegre nem triste. É um episódio de intervalo. Formou-o a alma portuguesa quando não existia e desejava tudo sem ter força para o desejar.

As almas fortes atribuem tudo ao Destino; só os fracos confiam na vontade própria, porque ela não existe.

O fado é o cansaço da alma forte, o olhar de desprezo de Portugal ao Deus em que creu e também o abandonou.

No fado os Deuses regressam legítimos e longínquos. É esse o segredo sentido da figura de El-Rei D. Sebastião.” (Pessoa, 1979, p. 98)
}

Fruto da pluralidade conflitual de perspectivas que caracteriza Pessoa, é de destacar que a atmosfera de sentido de 'Fado da Censura' nada tem a ver com o misticismo poético e profético desta sua reflexão sobre a teodiceia do fado; se bem que também esta postura seria provocatória para a mentalidade dominante no poder, pela menção ao Deus que abandonou Portugal e no qual, diz o poeta, o país já não acredita.

Na economia imagética do poema, o ar e o pó são figuras recorrentes para evocar a censura, numa sátira respiratória. O pó cinzento da censura é a substância que torna o ar irrespirável, numa crítica que deixa a Ideia raquítica, num contexto vigiado pela Guarda, que dá pancada numa esquadra. Um pó que entra pelos ouvidos e enche bocas, embotando os sentidos, impedindo a fala e a audição. $\mathrm{O}$ 
falar, o olhar e o ouvir mostram-se assim reféns dessa resposta da censura. Outro aspecto a salientar é a presença do olhar manipulador do outro, delator ou simplesmente controlador de comportamentos, personificado na figura de qualquer vizinho, na quarta estrofe; acentuando a condição de vigiados que é própria de uma sociedade sob o torniquete da censura.

Como o comenta José Barreto, em artigo de 2015, 'Fado da Censura' ficaria inédito por razões óbvias e "não consta que jamais tenha sido cantado". Pois passou a sê-lo a partir de agora, cumprindo noventa anos depois o desejo do poeta que o escreveu num estilo destinado a ser cantado aos quatro ventos, capazes de dissiparem o pó asfixiante da censura. A música que para ele concebi inspira-se na estrutura tradicional dos fados com esta forma métrica, mas introduzi uma variante para tornar a proposta musical mais diversificada para o cantor e para os ouvintes. Regra geral, a frase musical de cada uma das quatro estrofes de dez versos repetia-se ao longo do fado. Aqui optei por criar duas frases musicais diferentes que se alternam entre si em cada estrofe. E a primeira vez que 'Fado da Censura' se fez ouvir em público foi justamente em Paris, na sala mesma onde apresentei este artigo sob o formato de conferência, através de uma gravação de ensaio com piano digital por António Neves da Silva, feita na sala de música da Escola Superior de Teatro e Cinema. A sua estreia ao vivo dar-se-ia em concerto d'O Piano em Pessoa, no Teatro Garcia de Resende, em 7/10/2017, em Évora, a minha cidade-natal, de que há notícia ter sido visitada algumas vezes por Pessoa no final dos anos 20, quando a irmã Henriqueta e a sobrinha Nini residiram na capital alentejana.

\section{Fado da Censura, de Fernando Pessoa}

Neste campo da Política

Onde a Guarda nos mantém,

Falo, responde a Censura;

Olho, mas não vejo bem

Há um campo lamacento

Onde se dá bem o gado;

Mas, no ar mais elevado,

$\mathrm{Na}$ altura do pensamento,

Paira certo pó cinzento,

Um pó que se chama Crítica.

A Ideia fica raquítica 
Só de sempre o respirar.

Por isso é tão mau o ar

Neste campo da Política

Às vezes, nesta planura,

Se o vento sopra do Norte,

$\mathrm{O}$ pó torna-se mais forte,

E chama-se então Censura.

É um pó de mais grossura,

Sente-se já muito bem,

E a Ideia, batida, tem

Uma impressão de pancada,

Como a que dão numa esquadra

Onde a Guarda nos mantém.

O pó parece que chove,

Paira em todos os sentidos,

Enche bocas e ouvidos,

Já ninguém fala nem ouve.

Se a minha boca se move,

Logo à primeira abertura

A enche esta areia escura.

Só trago e me oiço tragar.

É uma conversa a calar.

Falo, responde a Censura

Vem então qualquer vizinho,

Dos que podem abrir boca;

No braço, irado, me toca,

E diz, "Não vê o caminho?

O seu dever comezinho

De patriota aí tem

Vê o caminho e não vem?!"

Para isso, bolas aos molhos!

Se este pó me entrou prós olhos,

Olho, mas não vejo bem. 


\section{Referências}

Barreto, José (2015). “A Poesia Política de Fernando Pessoa”. In Abril - Revista do Núcleo de Estudos de Literatura Portuguesa e Africana da UFF (Vol. 7, no. 14, pp.189-209). Niterói/Rio de Janeiro: Universidade Federal Fluminense.

(2017). "A última paixão de Fernando Pessoa". In Almeida, O., Medeiros P., Pizar-

ro, J. (Eds.). Pessoa Plural - Revista de Estudos Pessoanos/A Journal of Fernando Pessoa Studies (No. 12, pp. 596-641). Brown University/Warwick University \& Universidad de los Andes (https:// www.brown.edu/Departments/Portuguese_Brazilian_Studies/ejph/pessoaplural/issues.html). Acedido em 10/4/2018.

(2012). “O Fado do Bristol Club”. In Malomil. Blogger (17/12/2012). (http://malomil.blogspot.pt/2012/12/o-fado-do-bristol-club.html). Acedido em 10/4/2018.

Correia, Natália (2015). Não Percas a Rosa. Diário e algo mais (25 de Abril de $1974-20$ de Dezembro de 1975) / Ó Liberdade, Brancura do Relâmpago. Crónicas (15 de Julho de 1974 - 22 de Março de 1976). (Ângela Almeida e Vladimiro Nunes, Eds.). Lisboa: Ponto de Fuga.

Lopes, Teresa Rita (Ed.). (1993). Pessoa Inédito. Lisboa: Livros Horizonte.

Nery, Rui Vieira (2016). “O Fado e a ideologia do Estado Novo”. Prefácio in MOITA, Luiz. O Fado, Canção de Vencidos (1936). Edição fac-símile. Lisboa: A Bela e o Monstro/Museu do Fado.

Pessoa, Fernando (1986). Escritos Íntimos, Cartas e Páginas Autobiográficas. (António Quadros, Ed.). Mem Martins: Publicações Europa-América.

Pessoa, Fernando (1979). “O Fado e a Alma Portuguesa”. In Rocheta, M. I., Morão, P., Serrão, J. (Eds.) Sobre Portugal - Introdução ao Problema Nacional. Fernando Pessoa (p. 98). Lisboa: Ática.

Pessoa, Fernando (2006). Poesia 1931-1935 e não datada (Manuela Parreira da Silva, Ana Maria Freitas e Madalena Dine, Eds.). Lisboa: Assírio e Alvim.

Pessoa, Fernando (2015), Sobre o Fascismo, a Ditadura Militar e Salazar. (José Barreto, Ed.). Lisboa: Tinta da China.

Rosa, Armando Nascimento (2018). "Primórdios de Pessoa musicado”. In Rosa, N., Silva, A. N., O Piano em Pessoa (livreto do CD, pp. 10-11). Lisboa: Tradisom/Instituto Politécnico de Lisboa/Casa Fernando Pessoa.

Santos, Vítor Pavão dos (2014). O Fado da tua Voz, Amália e os Poetas. Lisboa: Bertrand Editora. 